\title{
Assessing the consistency between AVHRR and MODIS NDVI datasets for estimating terrestrial net primary productivity over India
}

\author{
R K Nayak ${ }^{1, *}$, N Mishra ${ }^{1}$, V K Dadhwal ${ }^{1}$, N R Patel ${ }^{2}$, M Salim ${ }^{1}$, K H RaO ${ }^{1}$ and C B S Dutt ${ }^{1}$ \\ ${ }^{1}$ National Remote Sensing Centre (NRSC), Indian Space Research Organization, Balanagar, Hyderabad, India. \\ ${ }^{2}$ Indian Institute of Remote Sensing (IIRS), Indian Space Research Organisation, Dehradun 403 004, India. \\ ${ }^{*}$ Corresponding author. e-mail: rabindrakumar_nayak@nrsc.gov.in
}

This study examines the consistency between the AVHRR and MODIS normalized difference vegetation index (NDVI) datasets in estimating net primary productivity (NPP) and net ecosystem productivity (NEP) over India during 2001-2006 in a terrestrial ecosystem model. Harmonic analysis is employed to estimate seasonal components of the time series. The stationary components (representing long-term mean) of the respective NDVI time series are highly coherent and exhibit inherent natural vegetation characteristics with high values over the forest, moderate over the cropland, and small over the grassland. Both data exhibit strong semi-annual oscillations over the cropland dominated Indo-Gangetic plains while annual oscillations are strong over most parts of the country. MODIS has larger annual amplitude than that of the AVHRR. The similar variability exists on the estimates of NPP and NEP across India. In an annual scale, MODIS-based NPP budget is $1.78 \mathrm{PgC}$, which is $27 \%$ higher than the AVHRRbased estimate. It revealed that the Indian terrestrial ecosystem remained the sink of atmospheric $\mathrm{CO}_{2}$ during the study period with $42 \mathrm{TgC}^{-1} \mathrm{NEP}$ budget associated with MODIS-based estimate against $18 \mathrm{TgC}^{-1}$ for the AVHRR-based estimate.

\section{Introduction}

In satellite remote sensing, the spectral reflectance data of vegetation $(\rho)$ on the range of visible (VIS) and near infrared (NIR) are related to the plant parameters such as leaf area index, biomass, and plant status such as stress and disease. One very extensively used transform of these spectral reflectances is the normalized difference in vegetation index (NDVI) defined as $\left(\rho_{\mathrm{NIR}}-\rho_{\mathrm{RED}}\right) /\left(\rho_{\mathrm{NIR}}+\rho_{\mathrm{RED}}\right)$ (Rouse et al. 1974). It characterizes the phenological state of the vegetation. It has been related to vegetation activity and to biophysical parameters like fraction of absorbed photosynthetically active radiation (Moulin et al. 1997). Net primary productivity (NPP) is the fundamental process in biosphere functioning and defined as the net accumulation of dry matter by green plants per unit time and space. NPP provides the energy and matter that drive the most biotic processes on the Earth. It represents the total carbon from the atmosphere that get assimilated into the biosphere at a given time. The NPP plays a crucial role in limiting the increasing rate of atmospheric $\mathrm{CO}_{2}$. Therefore, monitoring regional carbon storage in the form of NPP is indispensable for improving the state of the biosphere's health and system for carbon credit trading (Bonan 1995; Hunt et al. 1996; Chen et al. 2000).

Understanding of the global terrestrial Carbon (C) cycle has improved over the past few decades because of rapid establishment of atmospheric $\mathrm{CO}_{2}$

Keywords. Net ecosystem productivity; net primary productivity; carbon cycle; NDVI; CASA; India. 
measurement networks and vegetation inventories (Prentice et al. 2001); improved remote sensing methods for monitoring of land surface properties and enhanced ecosystem modelling (Potter et al. 1993; Turner et al. 2004). Large diversity of biome types and their functioning across the world causes uncertainties in $\mathrm{C}$ source and sink properties of terrestrial ecosystems at regional and continental scales (Tian et al. 2003; Piao et al. 2009). In the past, the long-term NDVI data records based on Global Inventory Modeling and Mapping Studies (GIMMS) extensively used in the terrestrial ecosystem modeling studies for the assessment of NPP budgets at regional and continental scales (Potter et al. 1993; Tian et al. 2003). These data were based on measurements from Advanced Very High Resolution Radiometer (AVHRR) sensors onboard National Oceanic and Atmospheric Administration (NOAA) satellites such as TIROS-N, NOAA series 6-12 and 14 functioning between the periods 1980 and 2006. Most of the remote sensing-based ecosystem models such as the Carnegie-Ames-Stanford Approach (CASA; Potter et al. 1993) calibrated against the GIMMS NDVI datasets. A number of studies were also carried out to assess seasonal and inter-annual variability of NPP for Indian ecosystem using GIMMS NDVI data in the CASA terrestrial biosphere model (Nayak et al. 2010, 2013). Nayak et al. (2013) have shown that the climate has significant control on the NPP over India with large decline over the Indo-Gangetic plains. More recently, these data have been used for assessing intra-seasonal variability of terrestrial biospheric $\mathrm{CO}_{2}$ fluxes over India during summer monsoons by Valsala et al. (2013), inter-annual variability and decadal change of NPP over India by Bala et al. (2013) and spatio-temporal variability of net ecosystem productivity (NEP) over the country in relation to the climatic variable by Nayak et al. (2015). Operational availability of this data was discontinued after 2006. On the other hand, the similar consistent NDVI time series data were operationally available from the measurements of Moderate-resolution Imaging Spectroradiometer (MODIS) sensor onboard the NASA's Terra (EOS AM) and Aqua (EOS PM) satellite sensors since early 2000. These data can be used complimentarily in combination with the ecosystem model for the similar studies pertaining to NPP budget assessment and C-cycle. Prior to use, proper adaptation of these data into the ecosystem model and its causative impact/differential-change in predicting NPP needs to be examined.

These NDVI datasets differ in terms of their spatial resolution, spectral range, temporal coverage, and associated atmospheric corrections that limit the direct comparison between the datasets (Teillet et al. 1997). MODIS employed narrower spectral bands at red (620-650 nm) and NIR (841-876 nm) together with necessary spectral bands for total atmospheric corrections comprising of molecular and aerosol scattering, ozone, water vapour absorption, etc. On the other hand, the AVHRR used relatively wider band (red: 585-680 $\mathrm{nm}$ and NIR: 730-980 nm) together with molecular scattering, and ozone and water vapour absorption bands for the computation of NDVI. MODIS sensors onboard the Terra and Aqua platforms have equator crossing times (ETC) of 10:35 AM local standard time (LST) and 1:30 PM LST, respectively while AVHRR sensors onboard the NOAA-16 and NOAA-17 platforms have ECT of approximately 10:15 AM LST and 2:00 PM LST, respectively. Pre-launch simulation results of the MODIS sensors suggest that NDVI values from MODIS are greater than those from AVHRR for a variety of plant chlorophyll content levels (Gitelson and Kaufman 1998). Subsequently a number of studies carried out to examine the consistency between these datasets for different regions across the globe (Gallo et al. 2005; Brown et al. 2006; Tarnavsky et al. 2008; Fensholt et al. 2009). These studies concluded that both the data compares well, however, consistency of their long-term records and continuity of future NDVI products in assessment of vegetation activity should be confirmed (Gallo et al. 2005; Chai 2011).

In view of the above, this study aims to examine the differences between two NDVI datasets at different time scales in their long-term records and to quantify associated differential change on NPP estimates over the Indian ecosystems through a common ecosystem model (CASA) driven by common climate parameter and soil and vegetation attribute maps. Our hypothesis is that if any difference between two estimates of NPP could be observed, that would be due to the differences in NDVI dataset. As the First Fourier Transform (FFT) shows the dominance of annual and semiannual harmonics in NDVI data (NPP estimates) over India (figure is not shown), we computed semi-annual and annual harmonic contributions along with stationary components (represent climatic mean) of both the time series. Residual of the time series (non-seasonal) can be used to characterize intra-seasonal and inter-annual variability. Current study mainly focuses on the comparison between two datasets in their seasonal cycles and inter-annual variability.

\section{Data and methods}

Time series of NDVI data used in this study are obtained from two different satellite sensors: MODIS and AVHRR for the common availability 
period between 2001 and 2006. The AVHRR-NDVI data used in the study are based on the long-term NDVI databases generated by Global Inventory Modeling and Mapping Studies (GIMMS) at an 8-km spatial resolution and 10-day temporal resolution during 1981-2006 (Tucker et al. 2005). The MODIS-NDVI bimonthly data over the study region obtained from the Land Processes Distributed Active Archive Center (LP DAAC). The data originally available in the form of $10 \times 10^{\circ}$ tiles in the Sinusoidal projection at $1 \mathrm{~km}$ spatial resolution. These data were re-projected in to the Lambert Azimuthal Equal Area projection of the AVHRR dataset at $8 \mathrm{~km}$. Then monthly composites of both AVHRR and MODIS images were prepared for the purpose of comparison and subsequent use in the CASA model for estimation of NPP and NEP. Both the NDVI data include all the necessary corrections associated with various perturbations associated with measurements such as cloud contamination, rain flag, etc.

The CASA algorithm uses following equation to estimate monthly NPP at each grid cell $(x)$ in month $t$

$$
\begin{aligned}
\operatorname{NPP}(x, t)= & \operatorname{fAPAR}(x, t) \times \operatorname{PAR}(x, t) \\
& \times \varepsilon^{*} T_{1}(x, t) T_{2}(x, t) W_{s}(x, t)
\end{aligned}
$$

where PAR is the photosynthetically active radiation (MJ) within 400-700 nm wavelengths, fAPAR is the fraction of absorbed PAR by canopy which is a function of NDVI, and $\varepsilon^{*}$ is the maximum light use efficiency for specific biome/land cover types which is adjusted for spatio-temporally varying stress scalars such as temperature and moisture.
The $T_{1}$ and $T_{2}$ represent monthly deviations from site-specific optimal temperature and from $20^{\circ} \mathrm{C}$, respectively, and $W_{s}$ refer to monthly scale relative soil moisture deficit based on difference between actual and potential evapotranspiration determined by soil water balance module of the CASA model. The model has mechanism that can link seasonal patterns of NPP to soil heterotrophic respiration (Rh). Difference between NPP and Rh represents net ecosystem productivity (NEP). We request readers to follow Potter et al. (1993) for the description of CASA algorithm in detail and Nayak et al. (2010) for its implementation for the Indian subcontinent. It is worth mentioning here that in this version of CASA model, we used different values of $\varepsilon^{*}$ and LAI for different vegetation types as presented in table 1 of Nayak et al. (2010).

Apart from NDVI data, CASA model is governed by climatic parameters such as precipitation, temperature, and solar radiation, and land cover and soil cover attribute maps. The climate data used here are of $0.5^{\circ} \times 0.5^{\circ}$ spatial resolution and are based on climatic database CRU TS 3.21 provided by the Climate Research Unit (CRU), University of East Anglia (UEA) (www.cru.uea.ac.uk/ $\mathrm{cru} /$ data/hrg). The land cover map (figure 1) used here is based on the land cover map of southeast Asia (Agrawal et al. 2003). The original land cover map was of $1 \mathrm{~km}$ spatial resolution that has been regridded at $8 \mathrm{~km}$ by Nayak et al. (2010) for use in the CASA model in their studies. The soil map is based on the Food and Agriculture Organization (FAO) of UNESCO's world soil map (Reynolds et al. 1999). As CASA uses the scaled values of NDVI between $\mathrm{NDVI}_{\min }$ and $\mathrm{NDVI}_{\max }$

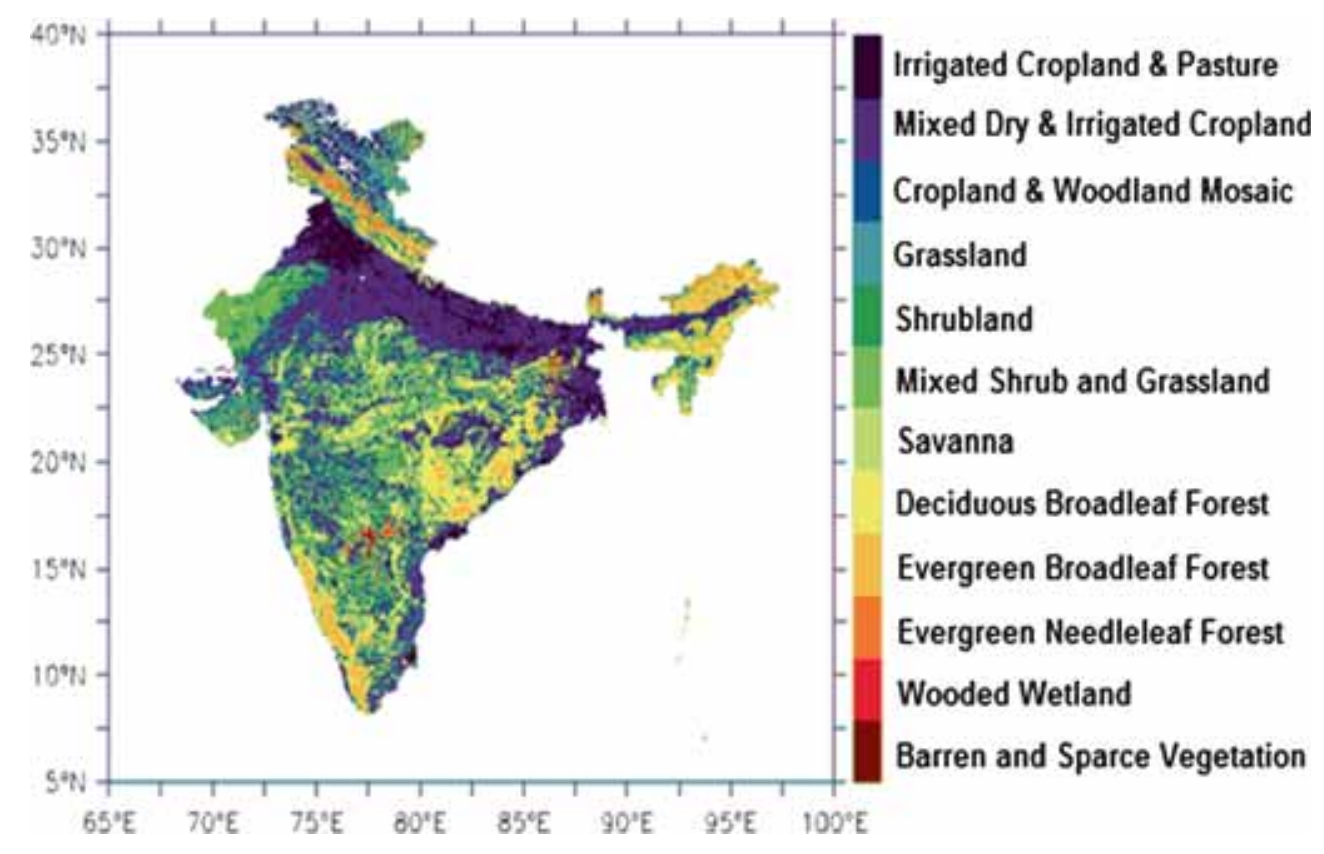

Figure 1. Land use/land cover map of India (adopted from Agrawal et al. 2003). 
for different land cover types, we made histogram analysis of NDVI for each land cover types for both the data sources. NDVI value at 5\%o level considered as $\mathrm{NDVI}_{\min }$ while $\mathrm{NDVI}_{\max }$ is taken at $95 \%$ level NDVI. Two sets of NPP and NEP simulations were carried out using MODIS-NDVI and GIMMSNDVI and respective NDVI scaling parameters. These scaling parameters are given in table 1 .

The time series of NDVI and NPP may exhibit variability at different time scales: seasonal, intraseasonal, inter-annual, and long-term increasing, or decreasing rate (trend). A seasonal cycle is a repetitive, predictable pattern seen in the timeseries. A non-seasonal cycle is a non-repetitive, possibly unpredictable, pattern in the time-series. A trend is a gradual upward or downward shift in the level of the series or the tendency of the series to increase or decrease over time. Harmonic analysis is a useful tool to characterize a time-series data with different climate regimes and transition regions. It decomposes a time-dependent periodic phenomenon into a series of sinusoidal functions, each defined by unique amplitude and phase values (Justino et al. 2010). The First Fourier Transform (FFT) of NDVI and NPP data shows dominating signals of annual and semi-annual harmonics (figures are not shown). Thus, the respective time series are fitted with annual and semi-annual harmonics through the least square procedure (LSP) as in the following:

$$
\operatorname{NPP}(t)=A_{0}+\sum_{i=1}^{2} A_{i} \cos \left(w_{i} t+\varphi_{i}\right)+\epsilon
$$

where $A_{0}$ is the stationary component that represents mean climatology of NPP; $\left(A_{1}, A_{2}\right)$ and $\left(\varphi_{1}, \varphi_{2}\right)$ terms denote the amplitude and phase angle of annual and semi-annual harmnics respectively; and $\varepsilon$ is the perturbation/residual term.
These annual and semi-annual harmonics together constitute seasonal cycle and the residual is considered as non-seasonal variability of the timeseries composed of intra-seasonal and inter-annual variability.

\section{Results}

\subsection{NDVI histograms comparison}

India is a tropical country with 3.28 million $\mathrm{km}^{2}$ landmass. The climate of the country varies from monsoonal in the south to temperate in the north. It has diverse vegetation cover (figure 1). The major land use and land covers are Irrigated Cropland \& Pasture (ICP), Mixed dry and Irrigated Cropland (MIC), Deciduous Broadleaf Forest $(\mathrm{DBF})$, Evergreen Broadleaf Forest (EBF), Mixed Shrub and Grassland (MSG), and Grassland (GL). Respectively they occupy $16.5 \%, 37 \%, 15 \%, 5.2 \%$, $10.8 \%$, and $4 \%$ of total geographical area of the country. The normalized cumulative histogram plots of NDVI for the major land cover types in India based on MODIS and AVHRR observations for the study period are presented in figure 2. Table 1 lists the $\mathrm{NDVI}_{\min }$ and $\mathrm{NDVI}_{\max }$ values for the datasets, respectively at $5 \%$ and 95\% levels on their histogram plots. Hereafter the values $\left(\mathrm{NDVI}_{\min }\right.$ and $\left.\mathrm{NDVI}_{\max }\right)$ are referred as NDVI scale. As presented in figure 2, the shapes of the histograms suggest that MODIS continuously measures higher values of NDVI than AVHRR for the land cover regions ICP, DBF and EBF. The NDVI scales respectively for both the data are $(0.306,0.765)$ and $(0.282,0.603)$ for ICP; $(0.305$, $0.791)$ and $(0.305,0.678)$ for DBF; $(0.487,0.879)$ and $(0.444,0.785)$ for EBF (table 1$)$. There exist relatively better agreements between two datasets for the regions dominated by MIC, GL and MSG,

Table 1. Minimum and maximum values of NDVI respectively at 5\% and 95\% levels for different land cover types in India.

\begin{tabular}{|c|c|c|c|c|c|}
\hline \multirow[b]{2}{*}{ Vegetation classes } & \multirow{2}{*}{$\begin{array}{c}\text { Landmass } \\
(\%)\end{array}$} & \multicolumn{2}{|c|}{ MODIS-NDVI } & \multicolumn{2}{|c|}{ GIMMS-NDVI } \\
\hline & & Min & $\operatorname{Max}$ & Min & Max \\
\hline Irrigated cropland \& pasture & 16.45 & 0.306 & 0.765 & 0.282 & 0.603 \\
\hline Mixed dry \& irrigated cropland mosaic & 36.83 & 0.185 & 0.695 & 0.179 & 0.551 \\
\hline Cropland woodland mosaic & 1.65 & 0.380 & 0.876 & 0.421 & 0.815 \\
\hline Grassland & 3.73 & 0.076 & 0.578 & 0.042 & 0.378 \\
\hline Shrub land & 0.98 & 0.046 & 0.233 & 0.061 & 0.202 \\
\hline Mixed shrub and grassland & 10.81 & 0.119 & 0.679 & 0.122 & 0.566 \\
\hline Savanna & 0.11 & 0.372 & 0.816 & 0.349 & 0.645 \\
\hline Deciduous broadleaf forest & 14.80 & 0.304 & 0.791 & 0.305 & 0.678 \\
\hline Evergreen broadleaf forest & 5.15 & 0.487 & 0.879 & 0.444 & 0.785 \\
\hline Evergreen needleleaf forest & 1.74 & 0.045 & 0.784 & 0.075 & 0.593 \\
\hline Wooded wetland & 1.74 & 0.071 & 0.743 & 0.190 & 0.596 \\
\hline Barren or sparse vegetation & 1.21 & 0.039 & 0.500 & 0.054 & 0.466 \\
\hline
\end{tabular}



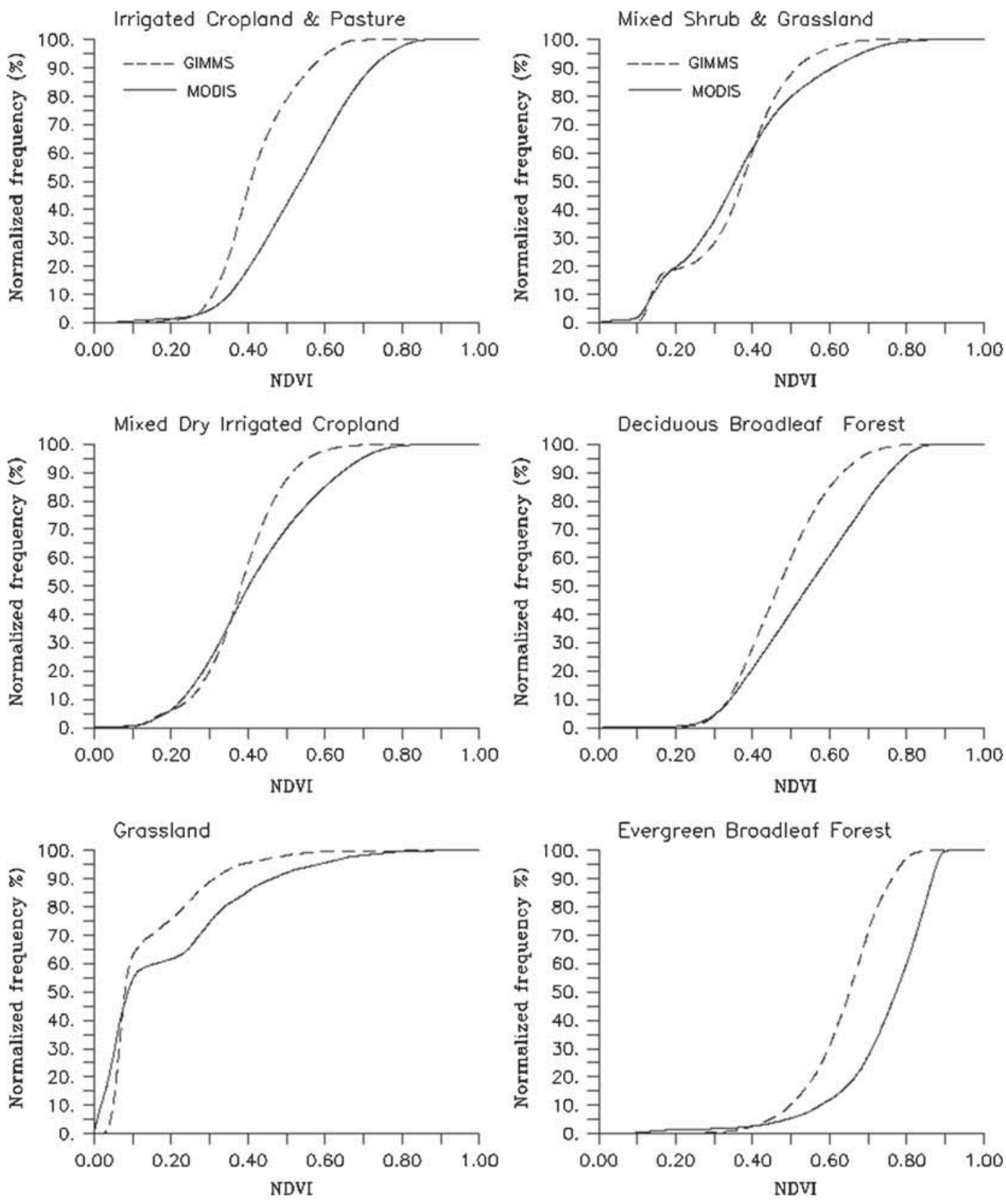

Figure 2. Cumulative normalized frequency plots for MODIS and AVHRR NDVI datasets over major land covers in India.

however with notable differences. Up to $40 \%$ (50\%, $65 \%$ ) pixels show smaller NDVI values in MODIS for the MIC (GL, MSG) land cover type as compared to AVHRR data and then MODIS estimated relatively higher values (figure 2 ). The NDVI scales for respective land cover classes are $(0.185,0.695)$, $(0.076,0.578)$, and $(0.119,0.679)$ for MODIS data against the AVHRR NDVI scales $(0.179,0.551)$, $(0.042,0.378)$ and $(0.122,0.566)$. This comparison between the two NDVI datasets is expected from their inherent sensors characteristics. As described in section 1, the MODIS has narrow spectral bands both for red and NIR regions against wider bands for AVHRR which could be the main reason to have larger values of NDVI in MODIS measurements than in AVHRR. In addition, the differential errors associated with atmospheric/environmental corrections and differences in respective ECT may be the additional/secondary reasons. Gitelson and Kaufman (1998) reported similar analyses during the pre-launch simulation of the MODIS sensors.

\subsection{Spatial patterns of NDVI harmonics}

The FFT of NDVI datasets exhibit dominating signals of annual and semi-annual cycles in respective time series (figures are not shown). These distinct annual and semi-annual characteristics of the vegetation signals over the country are mainly resulted from its natural geographical setting as northern 
tropical country with monsoonal climate features, vegetation covers, and agricultural practices. The stationary component (long-term mean) and contributions of semi-annual and annual cycles in the form of amplitude and phase were estimated by fitting the NDVI time series to the harmonics using LSP. Figure 3 shows the spatial patterns of stationary (A0) and amplitudes of the harmonics. The reconstructed mean seasonal cycle from these harmonics along with NDVI anomaly (observed NDVI minus the climatological mean) corresponding to the major land cover types: $\mathrm{EBF}, \mathrm{DBF}$ and cropland (ICP and MIC combined) were presented in figure 4. It revealed that the MODIS and AVHRR data exhibit the similar spatial patterns in their respective harmonics and stationary components, however with different magnitudes. MODIS has larger values in annual amplitudes and in stationary component than that of the AVHRR, while amplitudes of their semi-annual cycles are comparable. All these cases, large values of the stationary component observed over forest region followed by cropland and grasslands, and very small values over the deserted tracts on the western India. Semi-annual amplitude are large $(>0.15)$ over Indo-Gangetic plains and some parts of north-central India (Madhya Pradesh) dominated by crop and grassland by vegetation classes. This is clearly observed in the reconstructed seasonality of both the NDVI time series in figure 4 . On the other hand, annual amplitudes are large over most parts of the central and southern peninsular India dominated by mixed shrub and grassland, and deciduous broadleaf forest, and over northern and northeastern high altitude evergreen needle and broadleaf forests. In addition to this, both the NDVI time series exhibit significant non-seasonal variability composed of intra-seasonal and inter-annual variability. For instance, the forestland cover in figure 4 shows pronounced intra-seasonal variability during the summer-monsoon season (AprilAugust). This will be discussed further in section 4 . Summarily amplitudes of semi-annual and annual harmonics together with the stationary component could explain broad phonological characteristic signals associated with vegetation cover types in the country. These parameters can be used to study phonological characteristics of natural vegetation covers and their classification similar to the study of Wagenseil and Samimi (2006) for a dry savannah environment in Namibia, which is beyond the scope of the present research.
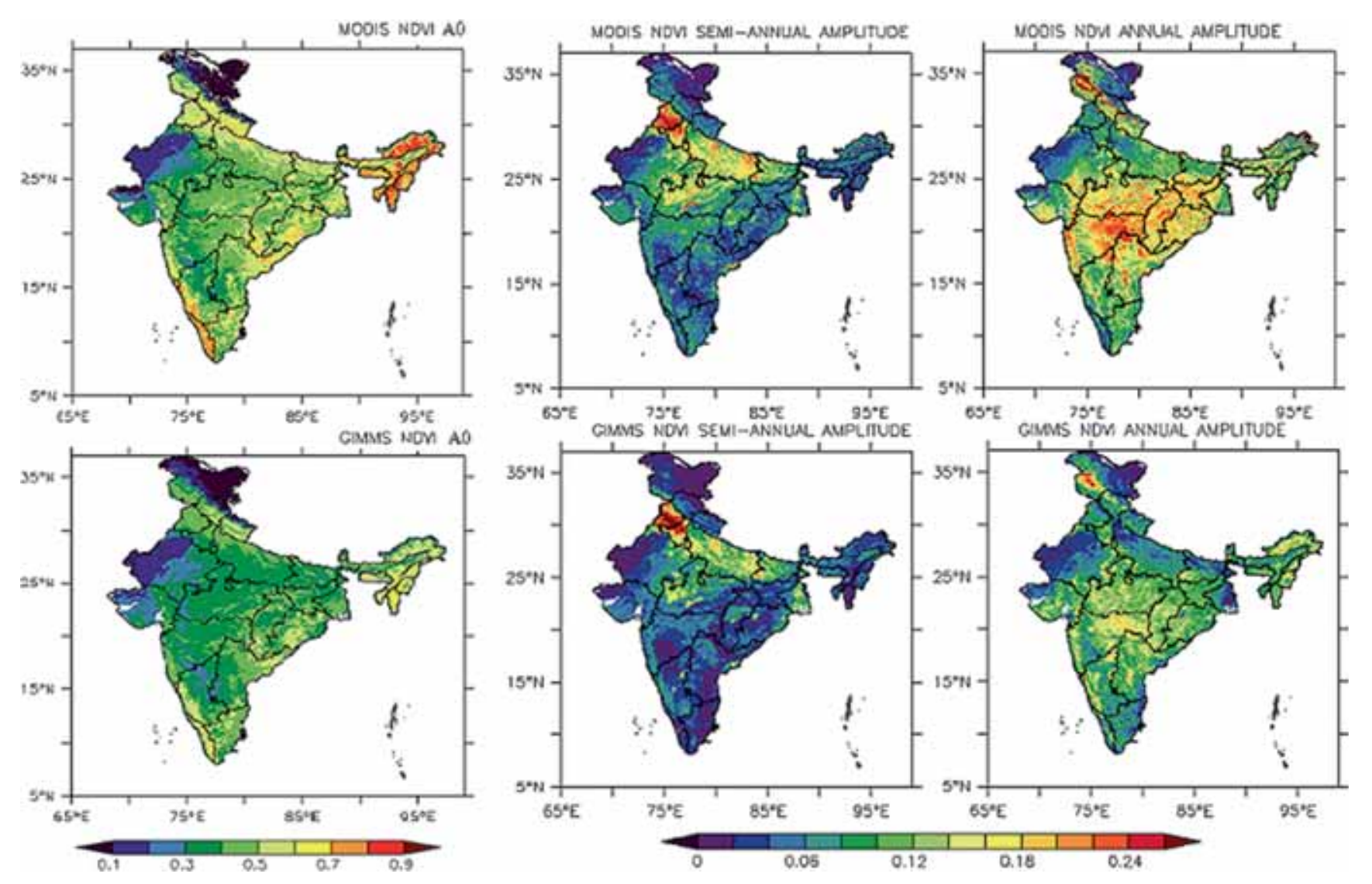

Figure 3. Stationary component (A0) and amplitudes of annual and semi-annual cycles of NDVI based on MODIS (upper panels) and AVHRR (lower panels) datasets. The left column represents stationary component, middle column represents semi-annual cycle, and right column represents annual cycle. 

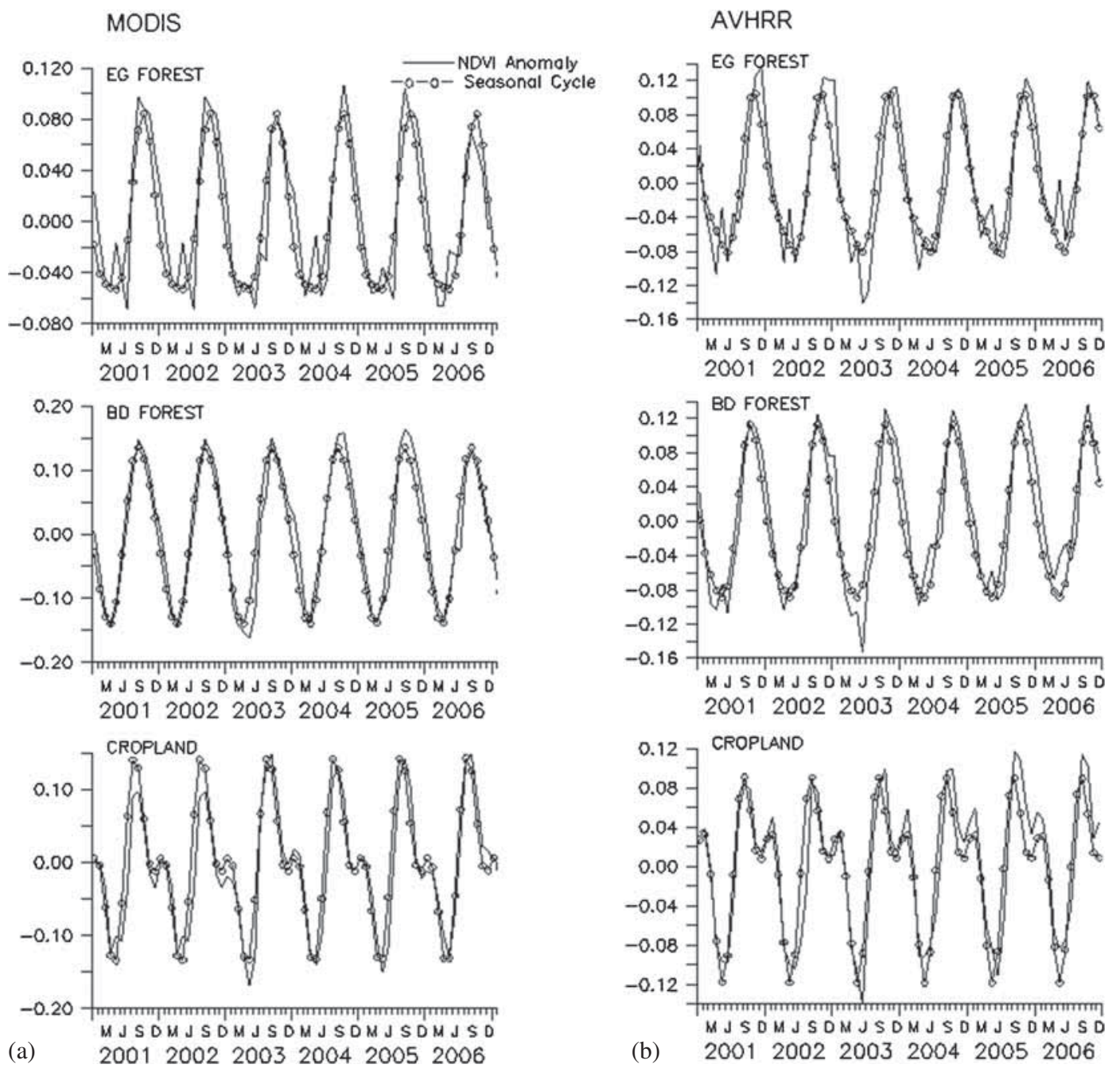

Figure 4. Time series of NDVI anomaly for major land cover types based on MODIS and AVHRR data and associated seasonality reconstructed based on semi-annual and annual components. The top panels are for evergreen broadleaf forest, middle panels are for deciduous broadleaf forest and bottom panels are for the cropland (see text for details).

Various statistical measures to quantify the consistency between the two datasets such as mean $(\mathrm{m})$, root mean square errors (RMSE), and coefficient of correlations $(r)$ calculated over different land cover types in the country are presented in table 2. For getting the feel about the land cover types/region, readers are requested to see figure 1. Mean value of MODIS (AVHRR) NDVI stationary component is large $0.7(0.55)$ for EBF followed by $0.57(0.45)$ for DBF, 0.46 (0.37) for ICP, 0.40 (0.34) for MIC, etc. Correlation between the stationary components of MODIS and AVHRR NDVI datasets are significantly high across the major vegetation covers in the country $(r>0.85)$. The RMSE between the two are large for the forest regions ( 0.2 for $\mathrm{EBF}$ and 0.12 for $\mathrm{DBF}$ ), moderate for cropland (0.12 for ICP) and small for grassland $(<0.09)$. The spatial pattern of semi-annual amplitude of MODIS-NDVI data has large mean for the croplands (0.15 for ICP and 0.8 MIC) and exhibits strong coherence with the semi-annual amplitude of the AVHRR NDVI dataset (high $r>0.8$ and small RMSE 0.034). Other land covers exhibit very small values of semi-annual amplitudes $(<0.4)$. The mean associated with the annual-amplitude is large $(0.15-0.16)$ for the savanna and evergreen needle leaf forest, moderate $(0.13-014)$ for the cropland, DBF and grasslands, and small (0.09) for the EBF. We also calculated the spatial patterns of correlations between two NDVI time series and between their seasonal components. As shown in figure 5, the correlation between the two datasets is very large $(r>0.7)$ over most parts of the country except the regions dominated by EBF (northeastern and southwestern parts of the country) and desert-tracts (shrub land) on the northwestern part of the country. These regions with low correlations respectively show very high and very low NDVI. On the other hand, strong correlation $(r>0.9)$ exists between their seasonal contributions over most of the regions across the country. 


\subsection{Spatial patterns of NPP and NEP harmonics}

The spatial maps of annual and semi-annual harmonics and stationary components of simulated NPP based on two sets of NDVI data are presented in figure 6 . Both the data exhibit similar features in their respective harmonics and the results are similar to NDVI datasets. The stationary component of MODIS-based NPP exhibit large values over the forest regions $\left(>70 \mathrm{gC} \mathrm{m}^{-2}\right.$ month $\left.^{-1}\right)$, moderate over the croplands $\left(40-70 \mathrm{gC} \mathrm{m}^{-2}\right.$ month $\left.^{-1}\right)$, small over the grassland $\left(20-40 \mathrm{gC} \mathrm{m}^{-2}\right.$ month $^{-1}$ ) and very small over the deserted tracts of Rajasthan and western Madhya Pradesh $(<20$ $\left.\mathrm{gC} \mathrm{m}^{-2} \mathrm{month}^{-1}\right)$. It has undergone large semiannual oscillations over the cropland-dominated regions on the Indo-Gangetic plains and central India and partly over southwestern coastal belts (amplitude $>30 \mathrm{gC} \mathrm{m}^{-2}$ month $^{-1}$ ). Semi-annual oscillations are insignificant over most parts of south peninsular India, deserted tracts on the northwestern India and forest dominated region on the northeast states and northern high altitude regions (amplitude $<15 \mathrm{gC} \mathrm{m}^{-2}$ month $^{-1}$ ). Annual oscillations of NPP are very significant (high values of amplitude corresponding to annual cycle) over most parts of the country except the deserted tracts of Rajasthan. Figure 7 shows the scatter plots between stationary components of two NPP simulations, and various statistical parameters characterizing the comparison between the respective harmonics are presented in table 3. There exists good agreement between the stationary components across the country except for the forest regions where NPP estimates corresponding to MODIS-NDVI are significantly larger than the AVHRR estimates. Large correlation between the amplitudes of semi-annual cycle were observed over different cropland and grassland regions with $r>$ 0.75, RMSE between 12 and16 $\mathrm{gC} \mathrm{m}^{-2}$ month $^{-1}$, and mean amplitudes $23-42 \mathrm{gC} \mathrm{m}^{-2}$ month $^{-1}$ for MODIS and 14-28 month $^{-1}$ for AVHRR (table 3). Mean amplitudes of annual cycles of MODIS-NPP remain $>40 \mathrm{gC} \mathrm{m}^{-2}$ month $^{-1}$ for most of the land cover types. These values are almost double of the semi-annual amplitude except over the region dominated by irrigated cropland and pasture by vegetation cover where the amplitudes are of similar in magnitude. The correlation between the annual harmonics are large for the grassland $(r=0.68)$, moderate for the mixed irrigated cropland and the broadleaf deciduous forest $(r=0.56)$ and relatively small for the broadleaf evergreen tree and irrigated cropland and pasture $(r=0.42$ and 0.46).

Due to the cyclic nature, semi-annual and annual harmonics have no contribution on the annual budget of NPP estimates; however, they play very 


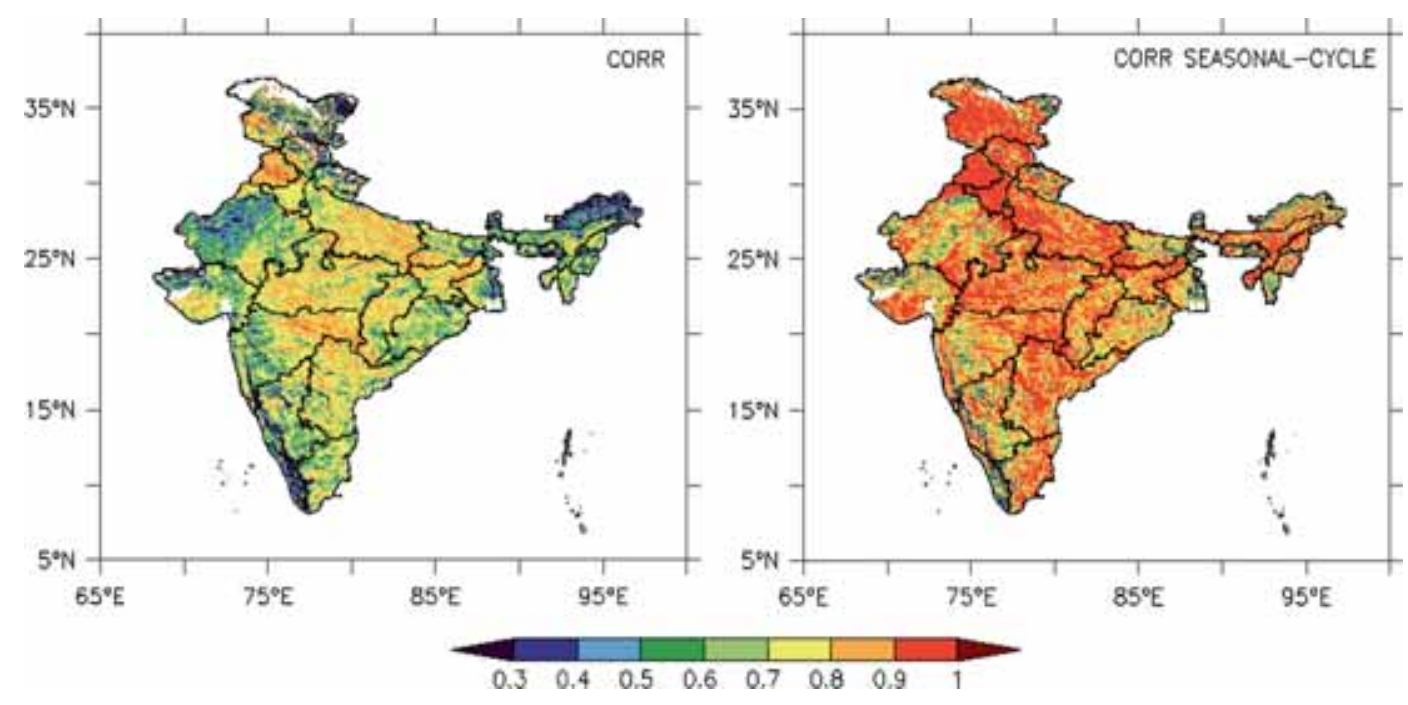

Figure 5. Left panels show the spatial patterns of correlation coefficients between the MODIS-NDVI time series and the AVHRR-NDVI time series. The same as for the seasonal components of NDVI datasets in the right panel.
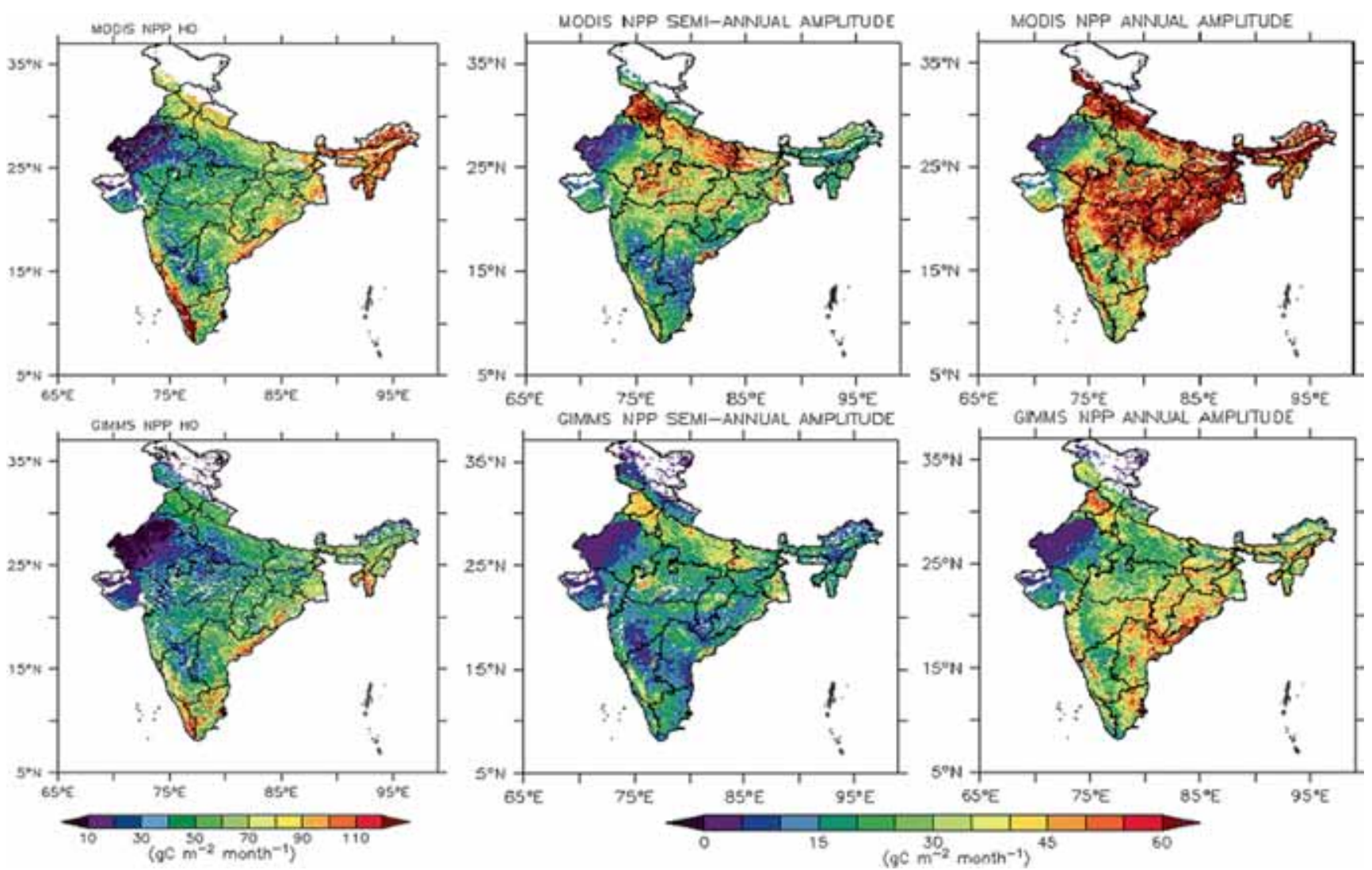

Figure 6. Stationary component (A0) and amplitudes of annual and semi-annual cycles of NPP based on MODIS-NDVI (upper panels) and AVHRR-NDVI (lower panels) datasets. The left column represents stationary component, middle column represents semi-annual cycle, and right column represents annual cycle.

significant role in controlling atmospheric $\mathrm{CO}_{2}$ variability. Thus, we integrated the stationary component to calculate national budget of NPP. The result suggests that annual NPP budget for India is $1.78 \mathrm{PgC}\left(1 \mathrm{Pg}=10^{15} \mathrm{~g}\right)$ for the MODIS-NDVI and
$1.40 \mathrm{PgC}$ for the AVHRR NDVI. Thus, MODIS estimates the NPP budget higher by $27 \%$ than the estimates based on AVHRR data.

The spatial patterns of amplitudes of annual and semi-annual harmonic of simulated NEP resemble 

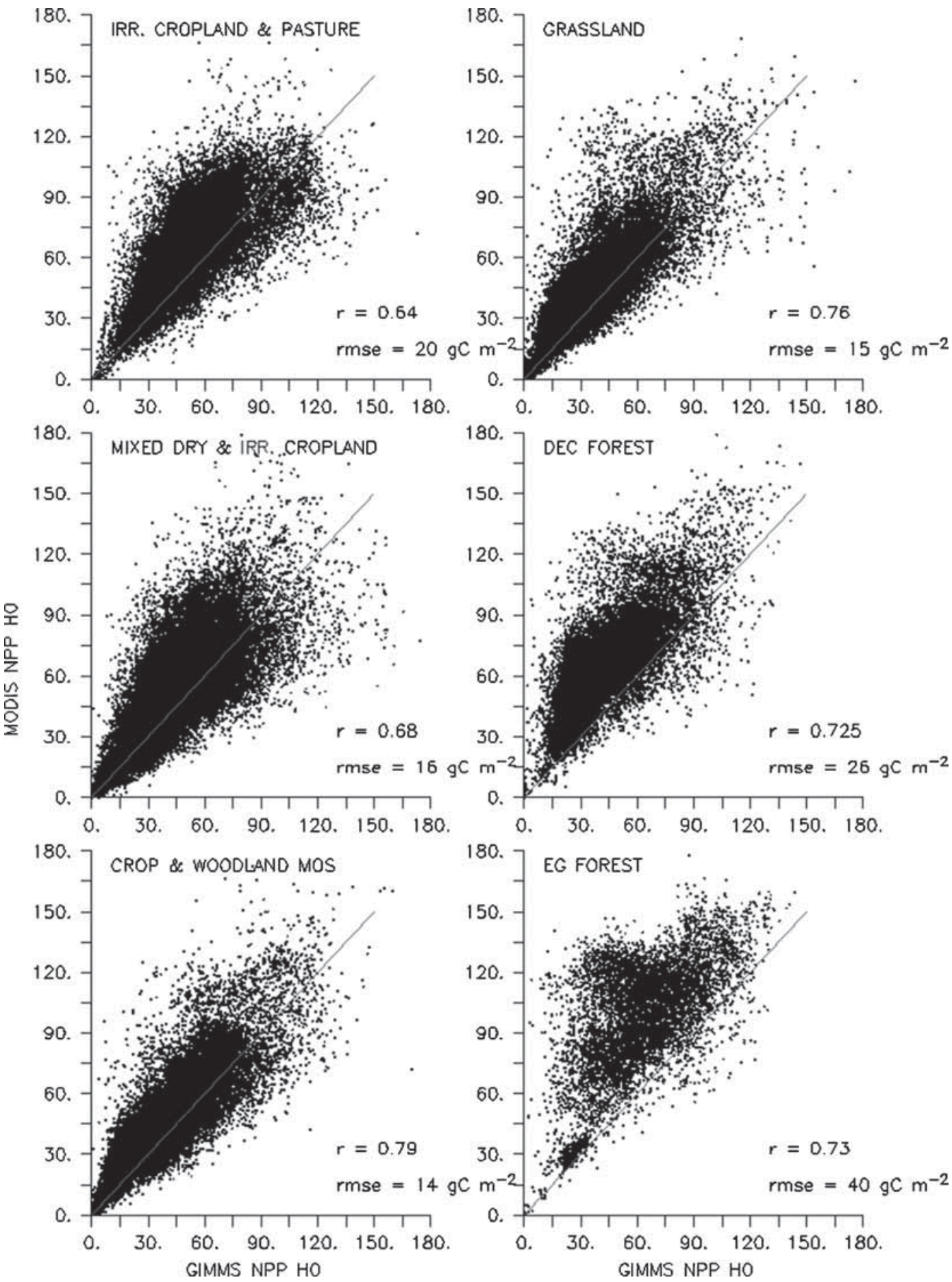

Figure 7. Scatter-plots between stationary component of simulated NPP based on MODIS-NDVI and AVHRR-NDVI datasets for major land cover types in India.

the NPP harmonics while the stationary component shows significant positive values over most parts of the country except over the flood-prone regions on the southeastern parts of Indo-Gangetic plains (Bihar and West Bengal) and Brahmaputra River basins in the northeast states (figure 8). The mean NEP values (stationary component) vary between -6 and $6 \mathrm{gC} \mathrm{m}^{-2}$ month $^{-1}$. Positive NEP indicates removal of atmospheric $\mathrm{CO}_{2}$ by the terrestrial ecosystem while negative NEP represents the opposite. Both simulations suggest that the total NEP budget for India is positive and significantly high indicating India is a net sink of atmospheric $\mathrm{CO}_{2}$. However, MODIS-based NEP budget for India is $42 \mathrm{TgC}^{-1}\left(1 \mathrm{Tg}=10^{12} \mathrm{~g}\right)$ while it is $18 \mathrm{TgC} \mathrm{y}^{-1}$ for the case of AVHRR-based estimates. The similar values of annual budget were estimated for the climatological years for the period 1981-2006 by Nayak et al. (2015) using the GIMMS NDVI in the CASA model. 
Table 3. Same as in table 2 but for simulated NPP based on MODIS-NDVI and GIMMS-NDVI data sets.

\begin{tabular}{|c|c|c|c|c|c|c|c|c|c|}
\hline \multirow[b]{2}{*}{ Vegetation classes } & \multicolumn{3}{|c|}{ Stationary (H0) } & \multicolumn{3}{|c|}{ Semi-annual cycle } & \multicolumn{3}{|c|}{ Annual cycle } \\
\hline & Mean & RMSE & $r$ & Mean & RMSE & $r$ & Mean & RMSE & $r$ \\
\hline Irrigated cropland \& pasture & $67(53)$ & 20 & 0.63 & $42(28)$ & 16.5 & 0.75 & $50(34)$ & 24 & 0.46 \\
\hline Mixed dry \& irrigated cropland mosaic & $48(40)$ & 16 & 0.67 & $26(17)$ & 12.5 & 0.76 & $40(25)$ & 20 & 0.56 \\
\hline Cropland woodland mosaic & $49(42)$ & 14 & 0.79 & $23(14)$ & 11.5 & 0.74 & $42(26)$ & 19 & 0.66 \\
\hline Grassland & $46(37)$ & 15 & 0.76 & $22(13)$ & 11 & 0.76 & $41(25)$ & 19 & 0.68 \\
\hline Shrub land & $46(37)$ & 16 & 0.83 & $19(12)$ & 10 & 0.69 & $38(25)$ & 18 & 0.68 \\
\hline Mixed shrub and grassland & $41(32)$ & 15 & 0.80 & $17(11)$ & 9.8 & 0.69 & $35(23)$ & 17 & 0.69 \\
\hline Savanna & $57(42)$ & 21 & 071 & $20(14)$ & 10 & 0.52 & $45(30)$ & 20 & 0.52 \\
\hline Deciduous broadleaf forest & $69(47)$ & 26 & 0.73 & $22(14)$ & 11 & 0.53 & $50(35)$ & 20 & 0.56 \\
\hline Evergreen broadleaf forest & $99(62)$ & 42 & 0.74 & $25(16)$ & 12 & 0.58 & $44(33)$ & 22 & 0.42 \\
\hline Evergreen needleleaf forest & $59(37)$ & 27 & 0.88 & $14(7.5)$ & 8 & 0.68 & $51(24)$ & 33 & 0.77 \\
\hline Wooded wetland & $33(27)$ & 7 & 0.91 & $13(9)$ & 6 & 0.89 & $27(18)$ & 12 & 0.95 \\
\hline Barren or sparse vegetation & $30(24)$ & 6 & 0.86 & $9(7)$ & 3 & 0.75 & $22(14)$ & 7 & 0.9 \\
\hline
\end{tabular}
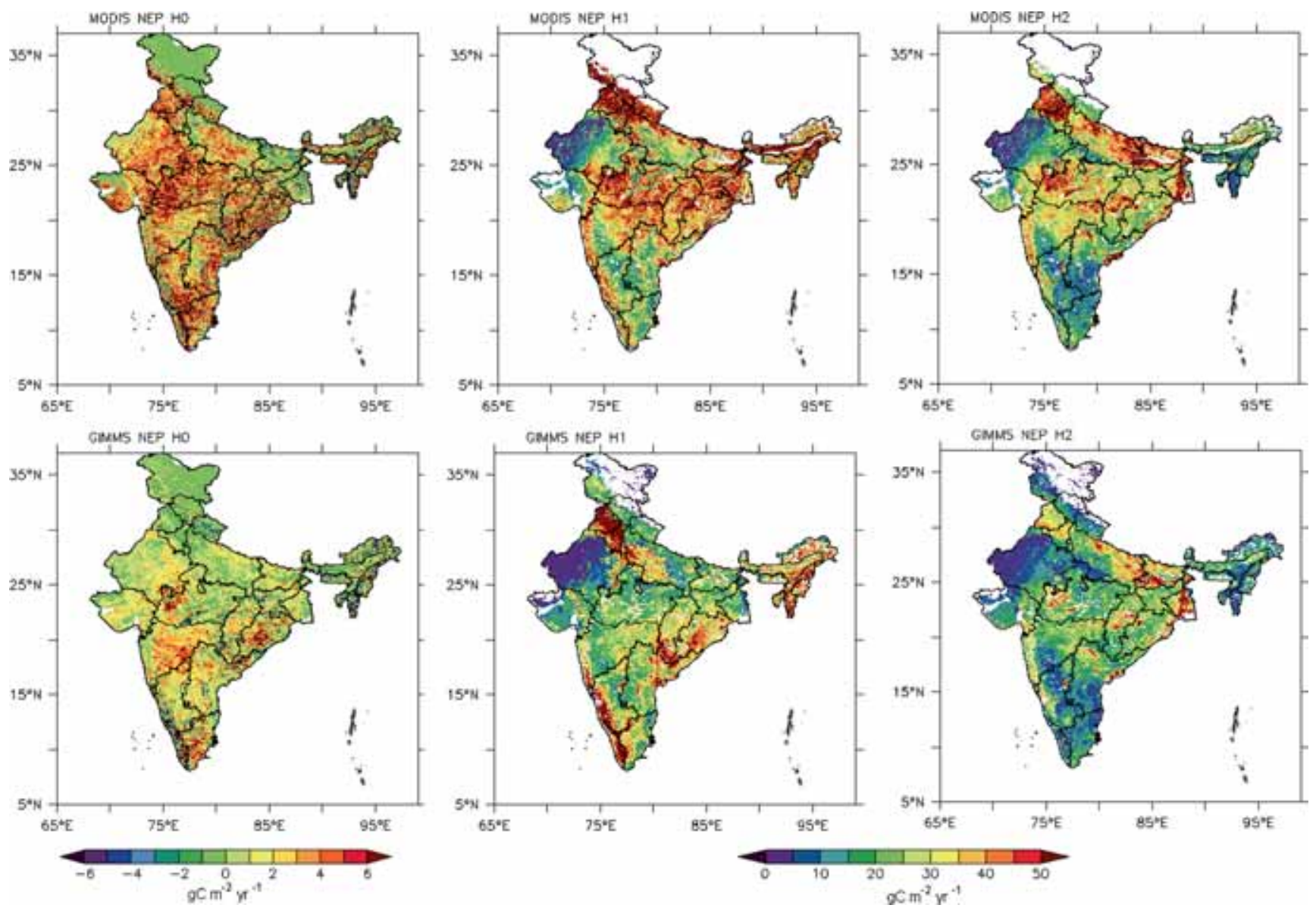

Figure 8. Stationary component (A0) and amplitudes of annual and semi-annual cycles of NEP based on MODIS-NDVI (upper panels) and AVHRR-NDVI (lower panels) datasets. The left column represents stationary component, middle column represents semi-annual cycle, and right column represents annual cycle.

\section{Discussion}

It was shown that both MODIS and AVHRR NDVI time series, exhibit highly coherent spatial patterns in their respective annual and semi-annual harmonics as well as in their stationary components. These coherent features with uniform high and low values describe different eco-regions of the country resulted from the long-term climatic and topographic characteristics/response of the regions. The strength of seasonal cycles (in the form of annual and semi-annual amplitudes) of MODIS is stronger than its counterparts of the AVHRR. This could be due to several reasons. MODIS 
sensor employed narrow spectral bands in red and NIR region for estimation of NDVI together with improved procedure for atmospheric corrections, especially for aerosol scattering and water vapour absorption over the AVHRR sensors (Vermote et al. 2002). AVHRR NDVI spectral bands in red and NIR are relatively wider and overlap with water vapour and aerosol absorption/scattering bands which could inhibit proper correction of errors due to water vapour and aerosol. India is a monsoonal country with strong seasonal variation in aerosol and water vapour loading in the atmosphere $(\mathrm{Li}$ and Ramanathan 2002; Prasad et al. 2005) that may not be considered appropriately by AVHRR algorithm for retrieving NDVI; however, further description and characterization of NDVI data associated with atmospheric correction is beyond the scope of present study.

In addition to the strong seasonal characteristics, both the data show significant non-seasonal (intraseasonal and inter-annual) variability. The difference between the NDVI time-series and reconstructed seasonal time-series for major land cover of the country are presented in figure 9. Both the data exhibit almost the similar variability with relatively larger magnitude for the AVHRR (GIMMS) data than the MODIS and the opposite was observed for their seasonal components, i.e., MODIS seasonal components are larger than the AVHRR. Other few notable features about nonseasonal characteristics are: both data exhibit large decline of NDVI during the period 20012003; enhanced values of NDVI during 2004-2006. We have discussed previously (in section 3 ) about some intra-seasonal variability apparently seen in the NDVI time series (figure 4) over the forest regions in the summer-monsoon season (AprilSeptember). We believe that this intra-seasonal and inter-annual variability in NDVI data were mainly due to the environmental stress factor for the vegetation, especially variability of the soilmoisture driven by monsoonal rainfall. Previously, Nayak et al. (2013) and Valsala et al. (2013) have respectively examined these issues in the model estimates of NPP and NEE (net ecosystem exchange of $\mathrm{CO}_{2}$ ) driven by NDVI datasets. Since our study period is limited to 6 years of common data availability with monthly composite NDVI
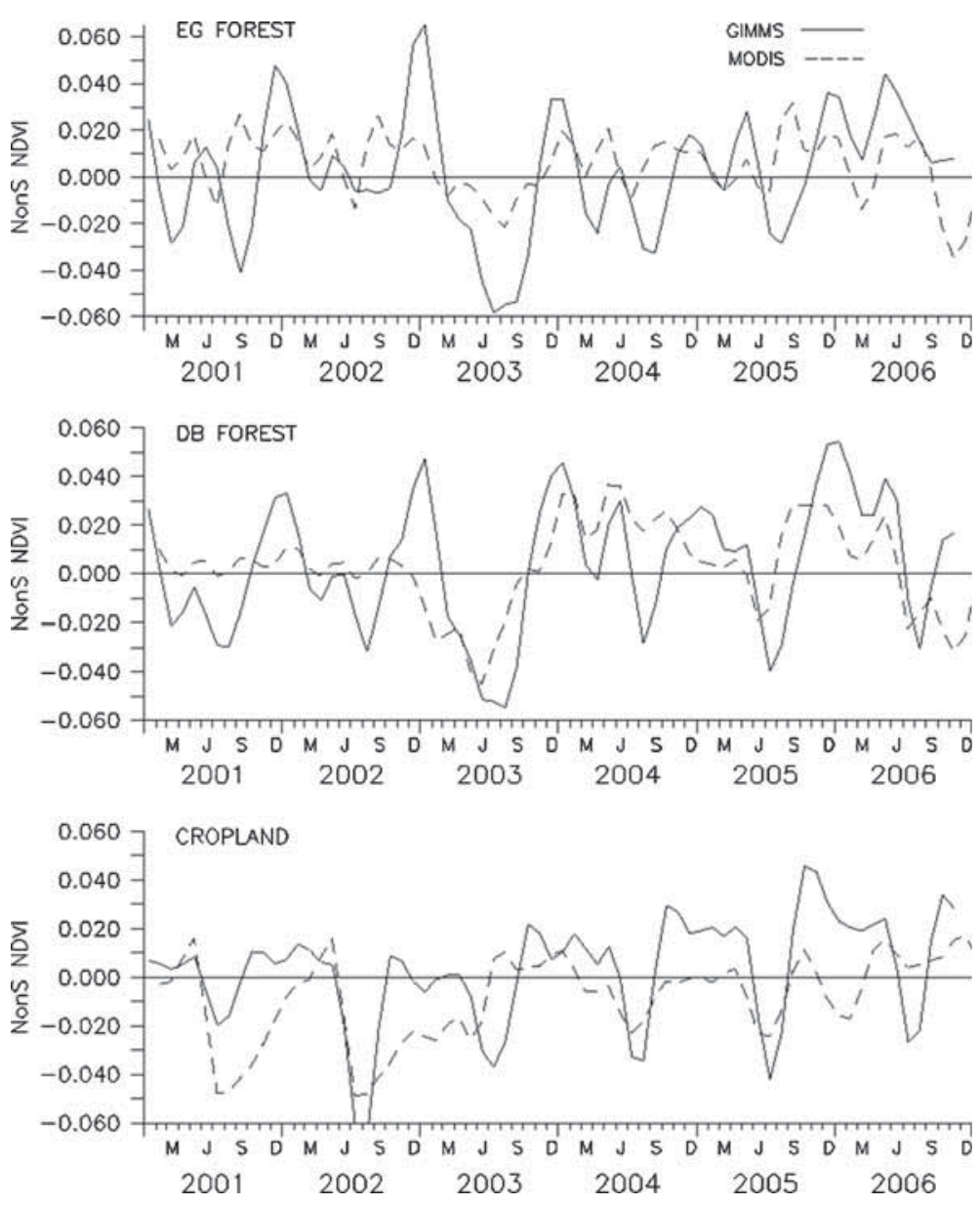

Figure 9. Non-seasonal component of the NDVI time series over the evergreen broadleaf forest (upper panel), deciduous broadleaf forest (middle panel), and cropland (lower panel) based on MODIS and GIMMS (AVHRR) datasets. 
datasets, we are not going to discuss further about the contributions and variability of intra-seasonal and inter-annual components of respective time series separately.

The similar strong correlation exists between simulated NPP based on two different NDVI datasets. The MODIS-based NPP estimate has significantly larger amplitudes of seasonal harmonics and stationary components than the AVHRRbased estimate. The annual NPP budget over India is estimated $1.78 \mathrm{Pg} \mathrm{C} \mathrm{yr}^{-1}$ for the case of MODIS that is $27 \%$ higher than the AVHRR-based estimate. The results remain the same when the budget is estimated for each year for the study period 2001-2006 (figure 10a). Both estimates exhibit continuous increase of national NPP budget from 1.35 (1.62) $\mathrm{PgCyr}^{-1}$ in 2001 to 1.55 (1.82) $\mathrm{PgCyr}^{-1}$ in 2006 for the case of AVHRR (MODIS) datasets at the rate of $32 \mathrm{TgCyr}^{-2}$. Although we cannot prove the fact that which NPP estimate is accurate due to lack of independent in-situ observations over India, we believe that AVHRR-based estimate is more accurate than the MODIS-based estimate. This is because the CASA model that we have used here to simulate NPP was originally calibrated against the AVHRR/GIMMS dataset and proven to be accurate enough (Potter et al. 1993) over the globe across different vegetations and over India for the croplands (Nayak et al. 2010).

The NEP budget for different years is also provided in figure 10(b). There exist strong inter-annul variation by the two estimates with average flux rate of $32 \mathrm{Tg} \mathrm{C} \mathrm{yr}-1$ in case of MODIS-NDVI and $11 \mathrm{Tg}$ $\mathrm{C} \mathrm{yr}^{-1}$ for AVHRR-NDVI. All these years MODISbased estimates are always positive (sink of atmospheric $\mathrm{CO}_{2}$ ) while AVHRR-based estimates has positive value for the years except 2002 and 2003 . These differences in both NPP and NEP estimates associated with different NDVI datasets could have large implications on the understanding of the role of terrestrial ecosystem on the control of atmospheric $\mathrm{CO}_{2}$ that needs to be investigated further in the future.

It is very apparent that higher values of NDVI corresponding to MODIS dataset could lead significantly different estimates of the NPP and NEP budgets as compared to the estimates based on GIMMS-NDVI dataset. We believe that this is not due to the errors in-built with NDVI datasets and in the modeling procedure. It is mostly due to overestimates of MODIS data in comparison with lower estimates of GIMMS-NDVI datasets.
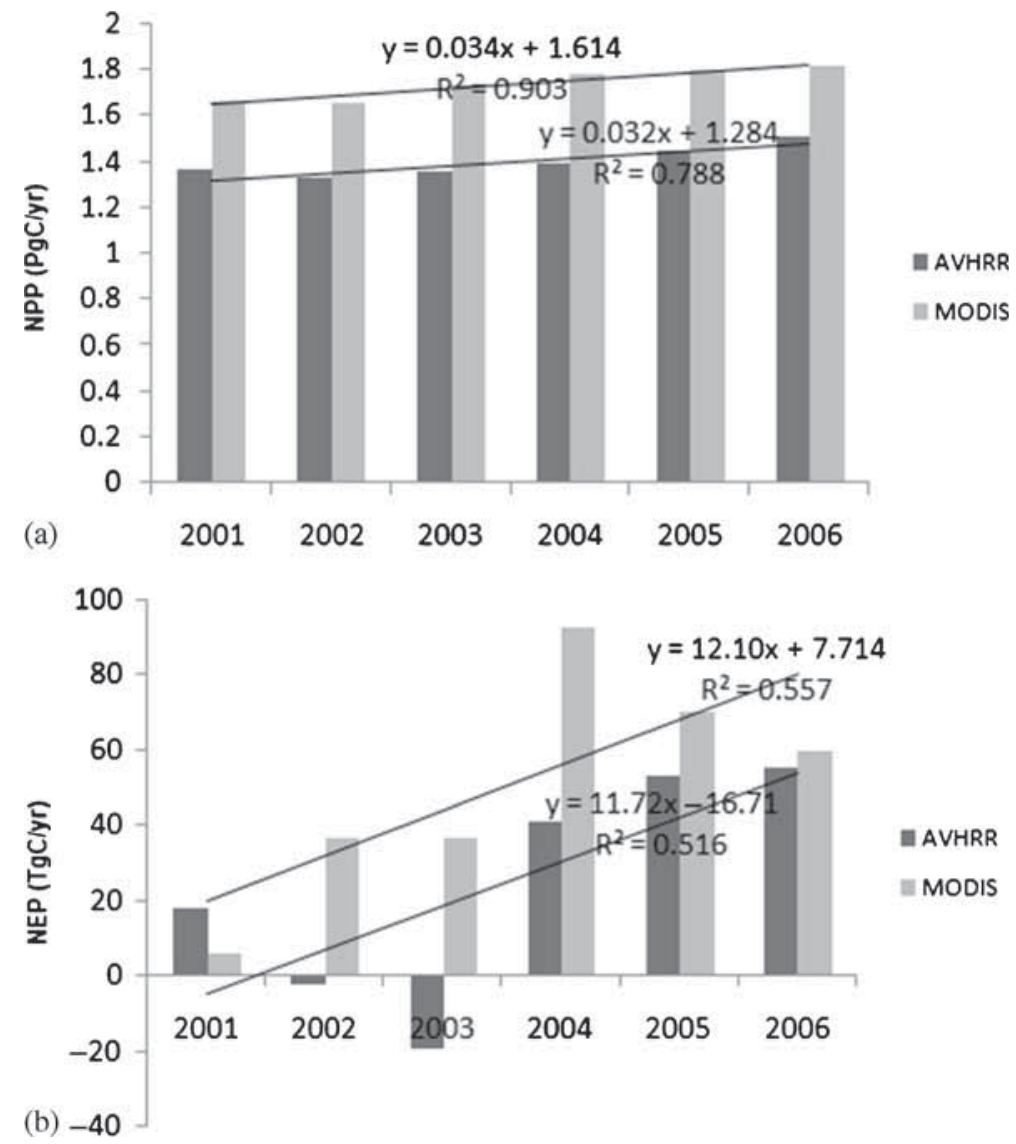

Figure 10. Bar plot shows inter-annual variability of NPP and NEP budgets over India corresponding to MODIS and AVHRR NDVI datasets. 
To understand the effect of errors in GIMMSNDVI dataset we made two more simulations by increasing the GIMMS-NDVI datasets by $10 \%$ (GF1) and decreasing by the same percentage levels (GF2). It can be noted that 10\% increase (decrease) in NDVI always remain higher side of the errors/variance associated with the AVHRR sensor. The NPP budgets of the country for each month based on these simulations are presented along with standard NPP simulations based on GIMMS (GIMMS F0) and MODIS NDVI (MODIS F0) datasets in figure 11. It can be observed that there exist significant difference in different estimates of NPP, however, all the simulations show almost the similar variations with the primary enhanced estimates of NPP during summer monsoon growing season (July-October) and the secondary enhancement during the winter monsoon season (January-March). The increase (decrease) of NDVI by $10 \%$ has enhanced the estimates of NPP by $18 \%$, increase (decrease) of NPP has happened mostly during the summer monsoon growing periods. All these simulated results (GF1, GF2, and GIMMSF0) remain much less than the results of MODISF0.

Climate variability may have significant influence on the estimates of the NPP and NEP budgets. Earlier, Nayak et al. (2013) partitioned the contribution of climate on the control of NPP linear growth rate and concluded that the large decline of NPP over the Indo-Gangetic plain during 19912006 was mainly due to the negative effect of the climate. In another study they had shown that inter-annual variability of NEP budgets had strong association with the climate variability (Nayak et al. 2015). The NEP budgets were positive for most of the extreme years with severe flood and drought conditions while the normal year have either positive or negative values. The precipitation-induced reduction of the NPP dominates the NEP variability in the dry years, whereas in good monsoon years the precipitation induced enhancement of the soil respiration (Rh) dominates the NPP budget. Since the present study comprises only 6 years, the effect of climate on long-term change of NPP budget has less meaning. However, the effect of climate
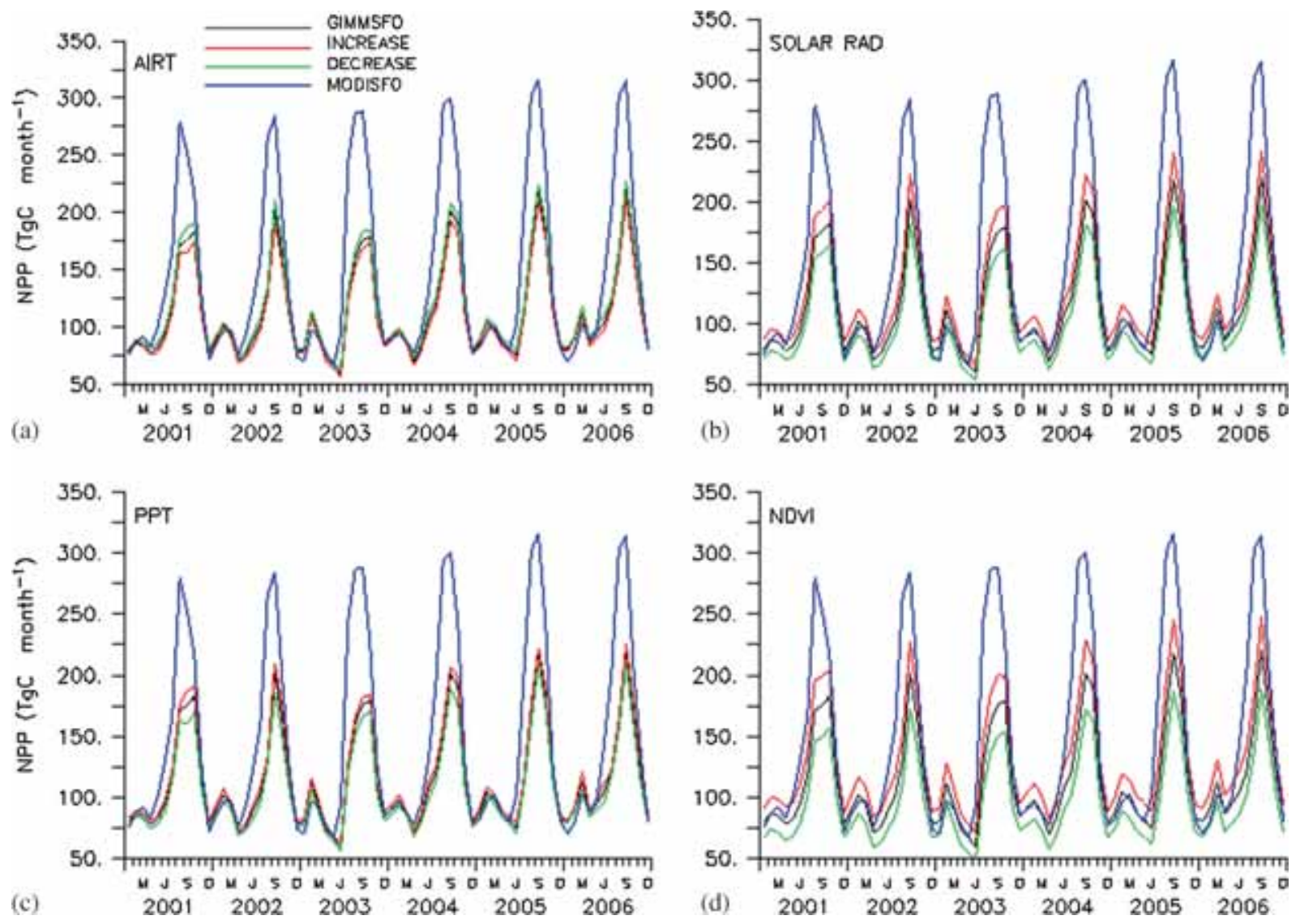

Figure 11. Monthly NPP budgets corresponding to the sensitivity experiments carried out with respect to the standard model run for GIMMS-NDVI datasets (GIMMSF0). (a) Increase (AIRT-1) and decrease (AIRT-2) air temperature by $5 \%$; (b) increase (SOL-1) and decrease (SOL-2) of solar radiation by $10 \%$; (c) increase (PPT-1) and decrease (PPT-2) of precipitation by $30 \%$ and (d) increase (GF1) and decrease (GF2) of NDVI by $10 \%$. The monthly national budget of NPP based on standard model run corresponding to MODIS-NDVI dataset (MODISF0) is also presented (see text for details). 
parameters on the estimate of NPP and NEP may be significant at the annual and sub-annual scales. Another important aspect that the errors associated with the CRU climate data may lead some uncertainty in the NPP estimates. It can be shown that the errors associated with CRU climate data may not contribute significant fraction of the NPP budget at national scale. It remains much lower than the difference between the estimates based on two NDVI datasets (GIMMS F0 and MODIS F0).

In order to examine the effect of climate and CRU climate data uncertainty, we made six additional simulations with respect to the standard simulation corresponding to the GIMMS-NDVI dataset (GIMMSF0). These are: (1) increase of $5 \%$ in air-temperature (AIRT-1); (2) decrease of airtemperature by $5 \%$ (AIRT-2); (3) increase of precipitation by $30 \%$ (PPT-1); (4) decrease of PPT by $30 \%$ (PPT-2); (5) increase of solar radiation by $10 \%$ (SOL-1) and (6) decrease of solar radiation by $10 \%$ (SOL-2). These percentage numbers are very significant and mostly remain at the upper levels of the respective climate variables. Increase of $30 \%$ in precipitation from the normal year precipitation leads to extreme flood situation while decrease to $30 \%$ leads to drought situation. Similarly increase (decrease) of air-temperature by $5 \%$ equivalent to $1^{\circ} \mathrm{C}$ at the base value $20^{\circ} \mathrm{C}$ may decide as the hot (cold) years. Increase or decrease of solar radiation by $10 \%$ equivalent to 30 Watts $/ \mathrm{m}^{2}$ corresponding to the base value 300 Watts $/ \mathrm{m}^{2}$ suggests higher side of the errors on the datasets. These simulated results are presented along with standard NPP simulation corresponding to GIMMS-NDVI (GIMMSF0) and MODIS-NDVI (MODISF0) datasets in figure $11(\mathrm{a}-\mathrm{c})$. It can be seen that the increase of temperature by $5 \%$ and precipitation by $30 \%$ could not make any significant difference in the NPP estimates. On the other hand, although the NPP estimate corresponding to $10 \%$ increase of solar radiation shows significant difference from the standard simulation (GIMMSF0), these values remain much lower than the MODIS F0.

\section{Conclusions}

Both MDIS and AVHRR NDVI datasets exhibit strong semi-annual oscillations over the IndoGangetic plains and north-central peninsular India, while annual oscillations are strong over the grassland dominated central peninsular India and forest dominated northeastern, northern, and western high altitude regions. MODIS has larger annual amplitude than the AVHRR dataset while their semi-annual amplitudes are comparable. The stationary components of respective time series are highly coherent. Amplitudes of semi-annual and annual harmonics together with the stationary component could explain broad characteristics of land cover types. The similar variability and coherences exist on the estimates of NPP over India based on both the NDVI datasets. In an annual scale, MODIS-based NPP budget is $1.78 \mathrm{PgC}$ which is $26 \%$ larger than AVHRR-based NPP budget $(1.40 \mathrm{PgC})$. Both the simulations suggest that Indian terrestrial ecosystem is a net sink of atmospheric $\mathrm{CO}_{2}$ with NEP budget $42 \mathrm{TgC}^{-1}$ for the MODIS-based estimates against $18 \mathrm{TgC}^{-1}$ for the case of AVHRR estimate.

\section{Acknowledgements}

This work is carried out under National Carbon Project (NCP) of ISRO Geosphere and Biosphere Program (ISRO-GBP). We sincerely thank the Director, IIRS for his encouragement and supports. We also thank MODIS and GIMMS teams at NASA for making available NDVI data at the public domains for use in this study.

\section{References}

Agrawal S, Joshi P K, Shukla Y and Roy P S 2003 SPOT VEGETATION multi-temporal data for classifying vegetation in south central Asia; Curr. Sci. 84(11) 14401448.

Bala G, Joshi J, Chaturvedi R K, Gangamani H V, Hashimoto H and Nemani R 2013 Trends and variability of AVHRR-derived NPP in India; Remote Sens. 5 810-829.

Brown M, Pinzón J, Didan K, Morisette J and Tucker C 2006 Evaluation of the consistency of long-term NDVI time series derived from AVHRR, SPOT-vegetation, SeaWiFS, MODIS, and Landsat $\mathrm{ETM}^{+}$sensors; Geosci. Remote Sens., IEEE Trans. 44(7) 1787-1793.

Bonan G B 1995 Land-atmosphere interactions for climate change system models: Coupling biophysical, biogeochemical and ecosystem dynamical processes; Remote Sens. Environ. 51 57-73.

Chai J 2011 A phenological comparison of NDVI products within contiguous United States, MS thesis, Virginia Polytechnic Institute and State University, 54p.

Chen W J, Chen J, Liu J and Cihlar J 2000 Approaches for reducing uncertainties in regional forest carbon balance; Global Biogeochem. Cycles 14 827-838.

Fensholt R, Rasmussen K, Nielsen T and Mbow C 2009 Evaluation of earth observation based long term vegetation trends - Intercomparing NDVI time series trend analysis consistency of Sahel from AVHRR GIMMS, Terra MODIS and SPOT VGT data; Remote Sens. Environ. 113(9) 1886-1898.

Gallo K, Lei Ji, Reed B, Eidenshink J and Dwyer J 2005 Multi-platform comparisons of MODIS and AVHRR normalized difference vegetation index data; Remote Sens. Environ. 99 221-231. 
Gitelson A and Kaufman Y 1998 MODIS NDVI optimization to fit the AVHRR data series - spectral considerations; Remote Sens. Environ. 66 343-350.

Hunt E R J, Piper S C, Nemani R, Keeling C D, Otto R D and Running S W 1996 Global net carbon exchange and intra-annual atmospheric $\mathrm{CO}_{2}$ concentrations predicted by an ecosystem process model and three-dimensional atmospheric transport model; Global Biogeochem. Cycles 10(3) 431-456.

Justino F, Setzer A, Bracegirdle T J, Endes D, Grimm A, Dechiche G and Schaefer C E G R 2010 Harmonic analysis of climatological temperature over Antarctica: Present day and greenhouse warming perspectives; Int. J. Climatol., doi: 10.1002/joc.2090.

Li F and Ramanathan V 2002 Winter to summer monsoon variation of aerosol optical depth over the tropical Indian Ocean; J. Geophys. Res. 107(D16) 4284, doi: 10.1029/2001JD000949.

Moulin S, Kergoat L, Viovy N and Dedieu G 1997 Global-scale assessment of vegetation phenology using NOAA/AVHRR satellite measurements; J. Climate 10 1154-1170.

Nayak R K, Patel N R and Dadhwal V K 2010 Estimation and analysis of terrestrial net primary productivity over India by remote-sensing-driven terrestrial biosphere model; J. Environ. Monit. Assess. 170(1-4) 195-213, doi: 10.1007/s10661-009-1226-9.

Nayak R K, Patel N R and Dadhwal V K 2013 Inter-annual variability and climate control of terrestrial of net primary productivity over India; Int. J. Climatol. 33(1) 132-142, doi: $10.1002 /$ joc. 3414 .

Nayak R K, Patel N R and Dadhwal V K 2015 Spatio-temporal variability of net ecosystem productivity over India and its relationship to climatic variables; J. Environ. Earth Sci. 74(2) 1743-1753, doi: 10.1007/s12665-015-4182-4.

Piao S, Fang J, Ciais P, Peylin P, Huang Y, Sitch S and Wang T 2009 The carbon balance of terrestrial ecosystems in China; Nature 458 1009-1013.

Potter C S, Randerson J T, Field C B, Matson P A, Vitousek P M and Mooney H A 1993 Terrestrial ecosystem production: A process model based on global satellite and surface data; Global Biogeochem. Cycle 7 811-841.

Prasad A K, Singh R P, Singh A and Kafatos M 2005 Seasonal variability of aerosol optical depth over Indian subcontinent: Analysis of multi-temporal remote sensing images, International Workshop IEEE, pp. 35-38.

Prentice I C et al. 2001 The carbon cycle and atmospheric carbon dioxide, In: Climate Change 2001: The
Scientific Basis, Contribution of Working Group I to the Third Assessment Report of the Intergovernmental Panel on Climate Change (eds) Houghton J T, Ding Y, Griggs D J, Noguer M, van der Linden P J, Dai X, Maskell $\mathrm{K}$ and Johnson C A, Cambridge University Press, pp. $183-237$.

Reynolds C A, Jackson T J and Rawls W J 1999 Estimated available water content from the FAO soil map of the world, global soil profile databases, pedo-transfer functions; NOAA National Geophysical Data Center, Boulder.

Rouse J W, Haas R H, Schell J A, Deering D W and Harlan J C 1974 Monitoring the vernal advancement of retrogradation of natural vegetation; NASA/GSFC Type III Final Rep., 371p.

Tarnavsky E, Garrigues S and Brown M 2008 Multiscale geostatistical analysis of AVHRR, SPOT-VGT, and MODIS global NDVI products; Remote Sens. Environ. 112(2) 535-549.

Teillet P, Staenz K and William D 1997 Effects of spectral, spatial, and radiometric characteristics on remote sensing vegetation indices of forested regions; Remote Sens. Environ. 61(1) 139-149.

Tian H, Melillo J M and Kicklighter D W et al. 2003 Regional carbon dynamics in monsoon Asia and its implications for the global carbon cycle; Global Planet. Change 37 201-217.

Tucker C J, Pinzon J, Brown M, Slayback D, Pak E W, Mahoney R, Vermote E and Saleous N E 2005 Extended AVHRR 8-km NDVI dataset compartable with MODIS and SPOT vegetation NDVI data; Int. J. Remote Sens. 26 4485-4498.

Turner D P, Ollinger S V and Kimball J S 2004 Integrating remote sensing and ecosystem process models for landscape-to-regional-scale analysis of the carbon cycle; J. BioSci. 54(6) 573-584.

Valsala V, Tiwary Y K, Pillai P, Roxy M, Maksyutov S and Murtugudde R 2013 Intraseasonal variability of terrestrial biospheric $\mathrm{CO}_{2}$ fluxes over India during summer monsoons; J. Geophys. Res. 118 752-769, doi: 10.1002/jgrg.20037.

Vermote E F, Saleous N Z E and Justice C O 2002 Atmospheric correction of MODIS data in the visible to middle infrared: First results; Remote Sens. Environ. 83 97-111.

Wagenseil H and Samimi C 2006 Assessing spatio-temporal variations in plant phenology using Fourier analysis on NDVI time series: Results from a dry savannah environment in Namibia; Int. J. Remote Sens. 27(16) 3455-3471. 